\title{
A Novel Interdisciplinary Health Professions Education Program at King Saud University: Strategy and Structure (Phase I)
}

\author{
Alnaami, M. ${ }^{1}$, Aretz, $T^{2}{ }^{2}$, Alshehri, M. ${ }^{1}$, Daud, M.Z. ${ }^{1}$, Almuammar, $A^{1}$
}

\begin{abstract}
Background: Interdisciplinary health education is one of the recommended strategies to improve health care systems as they become more complex, costly, and rely on care delivered by teams.

Objective: To improve health sciences education programs and their products through collaborative interdisciplinary co-education.

Methods: Based on student surveys, SWOT analysis, internal and external program accreditation reviews, and other evaluation initiatives for graduate health education programs, the need to improve health education became apparent in all health sciences colleges. The leadership group was involved in six faculty development exercises, three workshops were conducted in Riyadh, and they attended a total of three courses in Boston at the Harvard Macy Institute focusing on various aspects of the project as an agreement with Partners Harvard Medical International (PHMI).
\end{abstract}

Results: A strategic plan was developed. In addition, a governance structure of an inter-professional health education centre was designed in a way that encompasses all levels. The leadership group is responsible for the implementation of various functions of the centre that include advisory and content development, resources management, training, assessment and evaluation in a phased approach.

Conclusion: The proposed centre is an innovative approach to improve and foster interdisciplinary education across all health sciences colleges (HSCs) at King Saud University (KSU) developed with the involvement of all stakeholders, supported by outside facilitation and structured programs and exercises. The University will move quickly to implement the strategic plan and centre using a phased approach.

\section{Introduction}

Health professional education has undergone dramatic changes over the last century through four stages of innovation. In a significant shift from the scientific approach to health professional education commonplace in

\footnotetext{
${ }^{1}$ King Saud University, Riyadh, Saudi Arabia

${ }^{2}$ Partners Healthcare International, Boston, United States of America

Corresponding Author:

Mohammed Alnaami FRCSC, M Ed.

Director, Teaching, Learning, and Assessment Program Vice-Rectorship for Health Specialties, King Saud University

PO Box 2454, Riyadh 11451, Kingdom of Saudi Arabia

Fax: +966114670478; Telephone: +966114670482

Email: alnaami@ksu.edu.sa;

mohammedalnaami@gmail.com
}

Europe at the end of the 19 century, the Flexner era at the beginning of the $20^{\text {th }}$ century (Flexner, 1910) was noted for the idea of teaching basic sciences as the basis of clinical sciences and practice.

In the 1970s, problem-based learning was strongly promoted (Schmidt, 1983) in an attempt to integrate basic, clinical and social sciences through the use of problem scenarios. Competency/outcomes-based curricula became popular around the turn of this century (Albanese et al., 2008). Key competencies focus on demonstrable professional outcomes guided by local (Zaini et al., 2011) and global (Frenk et al., 2010) needs. The fourth significant innovation was put forward in 2010 in the Lancet Commissions Report. This report promotes health professionals' education and health care systems appropriate for the complex needs of the 21st century (echoing the Flexner 
Report of the 20th century); it advocates reforms in health profession curricula guided by two outcomes - interdependence in education and transformative learning (Frenk et al., 2010).

Our key aim is to develop new leaders who can effect meaningful and sustainable change in health professional education and healthcare systems. There is mounting evidence that inter-professional care improves patient outcomes (Reeves et al., 2008; O'Leary et al., 2011) and that there are positive experiences with inter-professional education (Hammick et al,. 2007; Hylin et al., 2007; Pelling et al., 2011). At KSU rather than initiating inter-professional programs at the student level as a first step, we hypothesized, given that inter-professional staff development and common resources are crucial elements in creating inter-professional programs (Hammick et al., 2007), that the creation of an Inter-professional Health Education Center ("the Center") would be a mission critical driver for our ultimate goals. These goals are: to improve health professional education programs and their products through collaborative inter-professional co-education, and to share this experience with other local universities. We understood from the beginning that this would be a major change effort, which needed to be carefully planned and executed in order to be effective. The following narrative is a case study of Phase 1 of our endeavor and the lessons learned in attempting such a university-wide change programme.

\section{Overall Approach}

Given that the proposed Center represented a major change at KSU, we employed a three stage process which has been used successfully in the past to affect curriculum reform as well as the creation of new programs, curricula and institutions (Aretz \& Armstrong, 2010).

Stage 1: Create a distinct Mission and Vision and translate this into a strategy that combines specific needs, regulatory requirements and opportunities, with institutional values and general goals based on models and benchmarks.

Stage 2: Make the desirable do-able by ensuring that the program plan is based on a solid business plan addressing not only program elements, but also the appropriate governance, necessary resources, and a concrete plan to address professional development needs.

Stage 3: Implement with quality assurance in mind by addressing success metrics from the outset.

\section{Needs Assessment:}

The needs assessment was based on the following data:

- Reviewing selected and relevant student and faculty surveys conducted prior to the National Commission for Assessment and Accreditation (NCAAA) visits.

- Performing an extensive strengths, weaknesses, opportunities, and threats (SWOT) analysis

- Reviewing program accreditation preparedness reports carried out by external reviewers for some HSCs.

- Reviewing other evaluations of initiatives for graduate health education programs by external academic and commercial consulting groups.

The result of these reviews and analyses indicated an obvious need to improve health professions education in all HSCs, especially in the areas of teaching, learning, and most importantly, assessment and evaluation. The core project group conducted a one-day strategic workshop at KSU during which the group discussed the various issues related to the programs and developed a preliminary strategic plan and set of goals focusing on these aspects, thereby providing the basis for the planning and implementation of the Center.

\section{External Consultation and Input}

KSU decided to enter into a consultative relationship with Partners Harvard Medical International [then Partners Healthcare International $(\mathrm{PHI})]$. PHI conducted a two-day strategic workshop in Riyadh attended by all internal stakeholders. The goal of this workshop was to explore commonalities and differences between the HSCs at KSU in their visions, missions, goals, competencies, and existing educational strategies.

Shortly after the workshop outlined above, the Vice-Rector for Health Specialties (VRHSs) and members of the core project group representing all themes attended a six-day course at the Harvard Macy Institute (HMI) in Boston, entitled "Leading Innovations in Health Care and Education". The group initiated the strategic planning framework and discussed it 
with the faculty and scholars during the course above. The core group and leadership of KSU felt strongly that faculty members from all of the HSCs needed to be involved from the very beginning of the project. $\mathrm{PHI}$ therefore conducted a three-day faculty development workshop in Riyadh entitled "Teaching-how-toTeach", which was attended by 35 key faculty educators from all HSCs. This workshop gave participants the opportunity to share and discuss recent developments in health sciences education and examine their strengths, weaknesses and applicability to the local culture and regulations. About six months after this key workshop, some of the leading group members and the Deans of the HSCs attended a 16-day course at $\mathrm{HMI}$ entitled "Program for Educators in Health Professions" to discuss and complete their assigned project tasks. After the course, the core project group synthesized all tasks and projects into a unified vision, mission statements, strategic goals and corresponding objectives (initiatives) in a two-day workshop in Riyadh.

The final intensive six-day course at $\mathrm{HMI}$ entitled "A System Approach to Assessment in Health Professions Education" was attended by the program director to finalize the strategic plan and structure of the program with consultation from HMI faculty and scholars. Throughout all Boston-based activities at HMI, $\mathrm{PHI}$ conducted special sessions and meetings to aid in the further development of the KSU project.

\section{Alignment of Values}

Aligning the values of KSU (available at KSU website) with the new Center was felt to be crucial to the sustainability and success of the new Centre. The vision, missions, and values for the program are shown in Table 1.

Table 1: The vision, mission, and values for the inter-professional health education centre

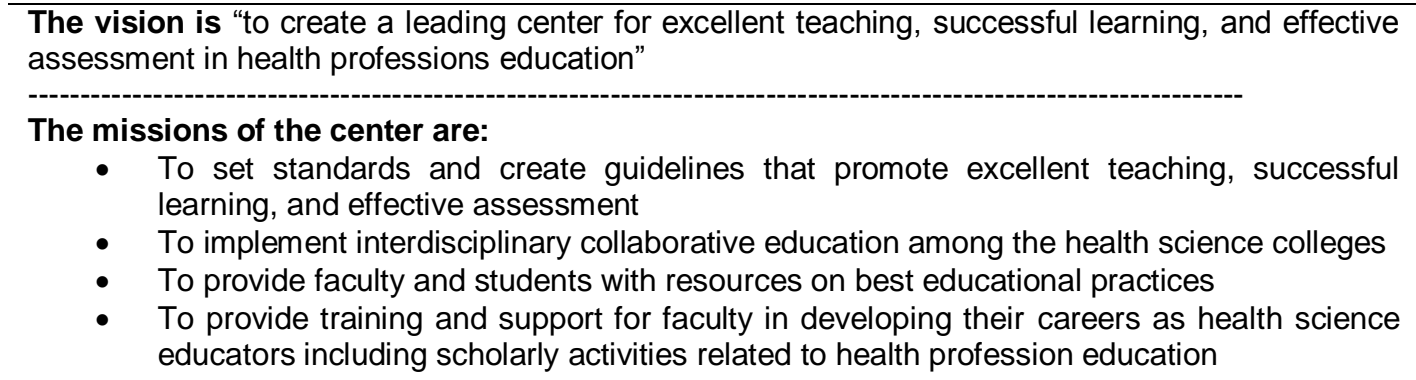

The values that are considered common among health science colleges at KSU include:

- Professionalism and Communication

- $\quad$ Learner-centered and Safe Learning Environment

- $\quad$ Critical Thinking and Self-directed Life-long Learning

- Social Accountability and Consciousness

- Teamwork and Equality

- Patient-Centered Care

- Commitment to Islamic values in health and disease

\section{Specific Strategic Goals, Action Plans and Key Performance Indicators (KPIs)}

It was important to work towards a jointly agreed set of common strategic goals with concrete actions steps and defined success metrics. The strategic goals of the program are presented in Table 2. We developed the specific strategic objectives (initiatives) for each goal, for example Goal 1 (Table 3), as one group in a two-day workshop assisted by $\mathrm{PHI}$. The various committees developed the details for each initiative that included actions plans and KPIs using the template recommended by KSU. The details of Goal 1/Initiative 1 are shown in Table 4 as an example. The remaining strategic goals, initiatives, action plans, and KPIs are beyond the scope of this document. However, they are available upon request.

All three committees met together and finalized the strategic plan including the proposed structure of the Center (Figure 1). The Center is housed in the VRHSs office. Such a central reporting structure has been found to be essential to the success of Inter- 
professional Education (IPE) efforts in universities of health sciences (Mitchell et al., 2006). The leadership committee of the Center is chaired by the Director of the Center and its members are the heads of the Teaching \& Learning (T\&L) units in the HSCs. The Deans or their nominees of the HSCs form the internal advisory board for the Center which communicates with the VRHS and the leadership of the Center. The external advisory board consists of national and international subject experts and will liaise with KSU through the leadership of the Center in such areas as collaboration, assistance, consultation, agreements, benchmarking, etc. The Assistant Vice-Rector for Development Affairs will no longer be part of the project after phase 1, while the Assistant Vice-Rector for Administrative Affairs will continue to support the Center in all administrative aspects including personnel, IT, communication, budgeting, and logistics.

The Center will have four main operational sections:
1. The advisory and content development section responsible for creating and reviewing strategies and guidelines, curricular development, and managing inter-professional courses and activities.

2. The resource management section is responsible for the database of the Center, literature resources, and other T\&L resources.

3. The training section is responsible for faculty development, online courses, simulation, and other common training and professional development functions.

4. The assessment and evaluation section is responsible for developing and maintaining a systems-based assessment and evaluation approach coordinated with the overall quality management activities.

Table 2: Strategic goals of the interdisciplinary health professions education program

\begin{abstract}
Learning goals:
Goal 1. To provide a high-quality learner-centered/self-directed learning experience for undergraduate and postgraduate students of the health science colleges that ensures best academic achievement, successful scholarship, and readiness for employment

Goal 2. To emphasize learning that adapts all learning theories each in its right context based on adult learning principles

Goal 3. To create a supportive learning environment where learners interact actively with the curriculum, patients and teachers in complex real-life problems

Goal 4. To build learners' self-awareness of values, attitudes, and beliefs that influence their learning achievement and actions to a high caliber professional career.
\end{abstract}

\title{
Teaching goals:
}

Goal 5. To promote and support distinguished and innovative educational excellence and scholarship among faculty.

Goal 6. To promote leadership and management qualities among health care faculty to cope with the rapidly changing global educational environment.

Goal 7. To develop faculty policies, career and incentives that support the essential role of teaching in light of competing priorities.

Goal 8. To promote interprofessional health education to develop insights, shared knowledge and teamwork skills that promote effective collaboration to deliver high quality care efficiency.

\section{Assessment and evaluation goals:}

Goal 9. To establish a system approach and "culture of assessment", in which evaluation and assessment in health sciences education encompass the assessment of the program and resources; students experience (process) and learning outcomes; and staff and teaching.

Goal 10. To develop a comprehensive approach to assessment that addresses all educational domains including knowledge, skills, and attitudes/values.

Goal 11. To enhance all relevant assessment methods that are in use for health sciences education, establish adequate measurements criteria, and make use of assessment and evaluation results for further improvement. 
Table 3: Goal 1 objectives (initiatives)

\begin{abstract}
Goal 1: To provide a high-quality learner-centered/self-directed learning experience for undergraduate and graduate students of the health sciences colleges that ensures best academic achievement, successful scholarship, and readiness for employment
\end{abstract}

- Provide means to get input from relevant stakeholders

- Create a culture that supports learner-centered learning

- Create exchange programs across the colleges

- Foster extra-curricular team projects

- Develop guidelines and provide support for faculty members in the use of learner-centered methods

- Develop faculty training and development programs in learner-centered

methodologies

- Create outreach programs to high schools and the Prep Program

- Help students to create their own learning objectives

Table 4. Goal 1-initiative 1 details; VRHSs, Vice-Rectorship for Health Specialties; SR, Saudi Riyals

Goal 1. To provide a high-quality learner-centered/self-directed learning experience for undergraduate and postgraduate students of the health science colleges that ensures best academic achievement, successful scholarship, and readiness for employment

Objective (1-1): Provide means to get input from relevant stakeholders Initiative (1-1): Identify all $\quad$ Responsible : stakeholders who may Teaching \& Learning have a valid input related to learner centered/self-
directed learning (SDL) (T\&L) Steering Committee,

\title{
Committee
}

Steering

VRHSs, Leadership

Committee

Partners : Deans of
Health Science
Colleges, Center for
Distinguished T\&L

Initiative description: To get input from relevant stakeholders involved

Requirements and interdependencies :

- $\quad$ Experts to develop and analyze the surveys

- Facilitators to distribute and collect the surveys

\section{Stakeholders :}

Faculty staff , students, employers, Postgraduate training directors

Action plans:

Estimated time :

Develop and adapt students' surveys on self-directed learning achievements

- Design and adapt faculty feedback surveys on learnercentered learning

- These surveys can be accessed online KPIs

1- More than $50 \%$ students' response rate Estimated budget

2- More than $25 \%$ faculty response rate

3- More than $50 \%$ graduates response rate

4- More than 25\% alumni response rate

5- More than $25 \%$ employers response rate

- Starts on Sept ember 2012

- Ends on December 2013
$5,000 \mathrm{SR}$ 
Figure 1. Structure of the Center. HS, Health Specialties; IT, Information Technology; A\&E, Assessment and Evaluation.

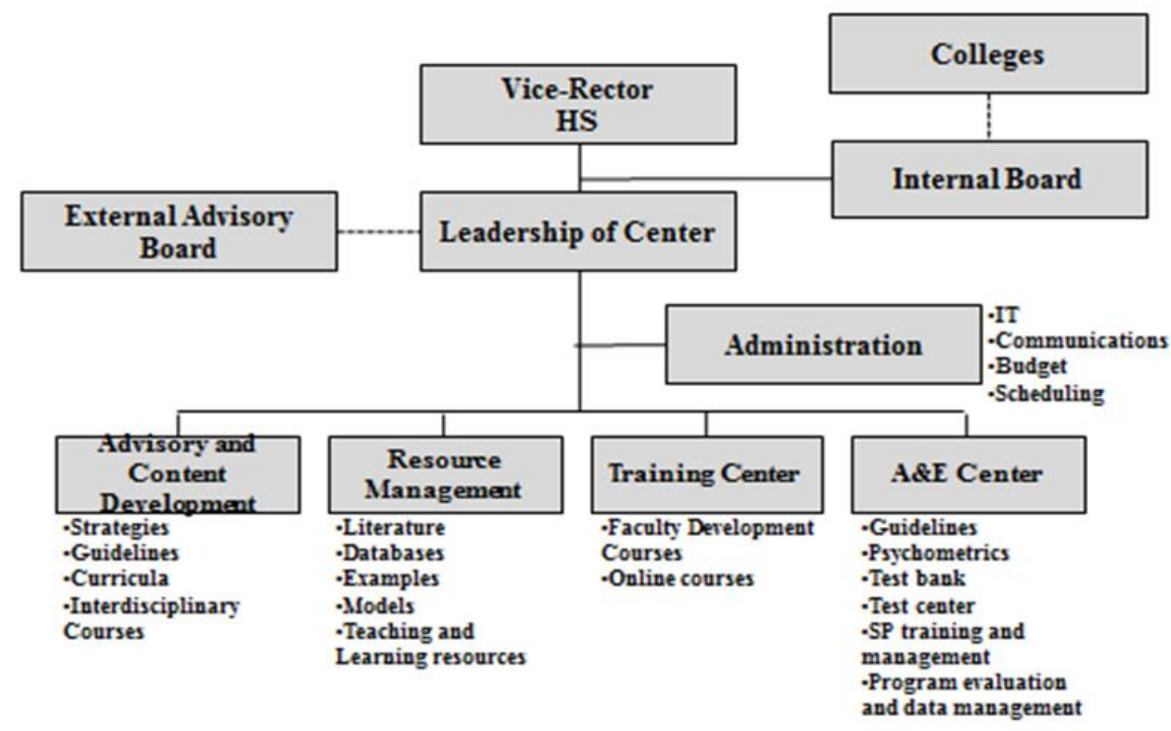

\section{Discussion}

Health professions education has played a central role in the vast improvements in health care systems and scientific research over the last century. More recent developments, however, including the rapid expansion of health sciences knowledge, the increasing complexity of care and use of information technology (IT) and new generations of learners have posed different challenges to educators and educational institutions. In order to cope with these changes and challenges, education across all health professions needs to be more adaptive, integrated, and transformative, such that the various fields become increasingly interdependent. Such interdependence in education may occur within a college, a university, a city, a country, or globally (Harden, 2006). One example of interdependent or integrated education is interprofessional education (IPE), which occurs when two or more professions learn with, from and about each other to improve collaboration and in the case of health services, the quality of care, as defined by the Center for the Advancement of Inter Professional Education (CAIPE) (Horder, 1991). Transformative learning is characterized by a shift from memorization to searching, analysis and synthesis of information for decision making; from seeking professional credentials to achieving core-competencies for effective team work in health systems; and from noncritical adoption of educational models to creative adaptation of global resources to address local priorities (Frenk et al., 2010).

There is an inter-dependency between education and health systems needing to respond to population health demands and therefore dependent on the supply of health professionals educated in such a way as to respond to new and challenging circumstances. In addition to these general drivers, our program was launched because of major changes and developments at KSU as it prepared for national accreditation by the NCAAA, and as it tried to respond to local market demands and needs.

Although these drivers provided a needed impetus for change and a feeling of urgency, the concrete changes that needed to be implemented were not clear from the outset. In addition, values felt to be common and important characteristics of all health professional graduates of the new millennium (UNESCO Asia and Pacific Regional Bureau for Education, 2002), and most demanded by the society needed to be supported by the Centre and were carefully chosen (Table 1). Our vision to create a Centre for excellent teaching, successful learning, and effective assessment in health professions education came about as the VRHS department at KSU was created and became responsible for many coordinating and support functions for all HSCs, thereby providing a central locus for oversight and planning. By concentrating on three areas - learning, teaching, and 
assessment, and not direct curricular involvement or oversight, the Centre focused on common needs of all colleges, while leaving the specific development of curricula in the hands of the individual colleges. Its supportive mission and activities will:

- help foster curricular reforms indirectly by setting standards and providing new guidelines (Genn, 2001; Grant 2010).

- promote inter-professional health professions education, as recommended for the $21^{\text {st }}$ century's health care and educational reforms (Kreizer et al., 2009; Frenk et al., 2010).

- provide resources on best educational practices for faculty especially in such challenging areas as simulations (Cook et al., 2011), e-learning (Vollmar et al., 2006), and communication and IT (Wilkinson et al., 2009). This particular mission was welcomed and supported by all HSCs as it was considered to be one of the most demanding areas in need of development and improvement, as indicated by faculty and student surveys.

- develop the skills of faculty staff in the science of pedagogy and research in health professions education through regular seminars and workshops in collaboration with the Deanship for Skills Development at KSU. Fulfilling these missions will also be useful in promoting and sustaining the desired changes for individuals and the organization (Wilkerson \& Irby, 1998).

Although learning, teaching, and assessment are integral and interdependent parts of health professional education, our strategic goals were divided into these different aspects of the curriculum and the learning experience (Table 2) to allow for more focused and smaller working groups and more efficient communication and completion of tasks. The three committees as outlined met twice as a full group to finalize the strategic plan as a whole and ensure that it was cohesive and comprehensive and not encompassing redundancy and unnecessary overlap. The learning goals listed are considered of paramount importance for health professional students of the new millennium (Mann et al., 2009; Israel et al., 2010), and they will guide the reform of the curricula of the HSCs at KSU.
The teaching goals are considered important for faculty staff to develop their skills in pedagogy and other areas (Hitchcock et al., 1992); to develop appropriate policies and incentives for their promotion (Green 2008); and to promote inter-professional health education (Freeth, 2010). Assessment and evaluation goals were designed to develop this area in all HSCs as it was found to be the least developed aspect of health science curricula according to reports by the visiting teams in preparation for the accreditation process. The aim is to create a system's approach to assessment and evaluation that covers:

- programs and resources

- students experience and learning outcomes

- $\quad$ staff performance and teaching outcomes

- use of assessment methods against learning domains (knowledge, skills, and attitude)

- $\quad$ establishment of adequate measurements criteria

The overall intention is to use assessment and evaluation results not only for student and faculty promotion, but also for further program and institutional improvement as part of an overall quality management approach (Epstein, 2007).

In conceiving and planning the Centre, KSU focused not only on what needed to be accomplished, but it was also very mindful of the necessary steps for a successful and sustainable change process. The work of Roberto and Levesque (2005) outlines four core processes - chartering, learning, mobilizing and realigning, as well as three enabling conditions (structural, procedural and emotional context) as required conditions for sustainable change.

In conclusion, the proposed Center is an innovative approach to improve and foster teaching, learning, and assessment across all HSCs at KSU, developed with the involvement of all stakeholders, supported by outside facilitation and structured programs and exercises. The University will move quickly to implement the Centre using a phased approach.

\section{References}

Albanese, M.A., Mejicano, G., Mullan, P., Kokotailo, P. \& Gruppen, L (2008) Defining characteristics of educational competencies, Medical Education, 42, pp. 248-255. 
Aretz, H.T. \& Armstrong E.L. (2010) Undergraduate Medical Education. In: Walsh K (ed.) The Oxford Textbook of Medical Education, Oxford University Press, Oxford, UK, pp. 325-39.

Cook, D.A., Hatala, R., Brydges, R., Zendeias, B., Szostek, J.H., Wang, A.T., Erwin, P.J. \& Hamstra, S.J. (2011) Technology-enhanced simulation for health professions education: a systematic review and meta-analysis, Journal of American Medical Association, 306, pp. 978-988.

Epstein, R. (2007) Assessment in Medical Education, New England Journal of Medicine, 356, pp. 387-396.

Flexner, A. (1910) Medical education in the United States and Canada: $A$ report to the Carnegie Foundation for the Advancement of Teaching, The Carnegie Foundation for the Advancement of Teaching, New York.

Freeth, D. (2010) Inter-professional education in Understanding Medical Education, In. Swanwick T. (Ed.), Association for the Study of Medical Education (ASME), Wiley and Blackwell, Oxford, UK, pp. 53-68.

Frenk, J., Chen, C.L., Bhutta, Z.A., Cohen, J., Crisp, N., Evans, T., Fineberg, H., Garcia, P., Yang, K., Kistnasamy, P., Kelley, B., Meleis, A., Naylor, D., Pablos-Mendez, A., Scrimshaw, S., Reddy, S., Sepulveda, J., Serwadda, D. \& Zurayk, H. (2010) Health professionals for a new century: transforming education to strengthen health systems in an interdependent world, Lancet, 376, 9756, pp. 19231958.

Genn, J.M. (2001) Curriculum, environment, climate, quality and change in medical education - a unifying perspective, AMEE Medical Education Guide No. 23 (Parts 1\&2), Medical Teacher, 23, pp. 337-454.

Grant, J. (2010) Principles of curriculum design, In: Understanding Medical Education, In. Swanwick T (Ed), by the Association for the Study of Medical Education (ASME), Wiley and Blackwell, Oxford, UK, pp 1-15.

Green, R.G. (2008) Tenure and promotion decisions: The relative importance of teaching, scholarship, and service, Journal of Social Work Education, 2, pp. 117-122.

Hammick, M., Freeth, D., Koppel, I., Reeves, S. \& Barr, H. (2007) A best evidence systematic review of interprofessional education, BEME Guide No.9, Medical Teacher, 29, pp. 735-751.

Harden, R.M. (2006) International medical education and future directions: A global perspective, Academic Medicine, 81, pp. 22-29.

Hitchcock, M., Stritter, F. \& Bland, C. (1992) Faculty development in health professions: Conclusions and recommendations, Medical Teacher, 4, pp. 295-309.
Horder, J. (1991) Centre for the Advancement of Interprofessional Education (CIPE): striving for collaboration, Nursing, 4, pp. 16-18.

Hylin, U., Nyholm, H., Mattiasson, A.C. \& Ponzer, S. (2007) Inter-professional training in clinical practice on a training ward for healthcare students: a twoyear follow-up, Journal of Inter-professional Care, 21, pp. 277-288.

Israel, B.A., Cummings, K.M., Dignan, M.B., Heaney, C.A., Perales, D.P., Simons-Morton, B.G. \& Zimmerman, M.A. (2010) Evaluation of Health Education Programs: Current Assessment and Future Directions. Health Education Research, 25, pp. 965-978.

Kreizer, M.J., Kligler, B. \& Meeker, W.C. (2009) Health professions education and integrative health care, Explore, 5, pp.212-227.

Mann, K., Gordon, J. \& MacLeod, A. (2009) Reflection and reflective practice in health professions education: a systematic review. Advanced Health Science Education: Theory and Practice Journal, 14 , pp. 595-621.

Mitchell, P.H., Belza, B., Schaad, D.C., Robins, L.S., Gianola, F.J., Odegard, P.S., Kartin, D. \& Ballweg, R.A. (2006) Working across the boundaries of health professions disciplines in education, research, and service: the University of Washington Experience, Academic Medicine, 81, pp. 891-896.

O'Leary, K.J., Buck, R., Fligiel, H.M., Haviley, C., Slade, M.E., Landler, P.M., Kulkarni, N., Hinami, K., Lee, J., Cohen, S.E., Williams, M.V. \& Wayne, D.B. (2011) Structured interdisciplinary rounds in a medical teaching unit: improving patient safety, Archives of Internal Medicine, 171, pp. 678-684.

Pelling, S., Kalen, A., Hammar M. \& Wahlström, O. (2011) Preparation for becoming members of health care teams: findings from a 5-year evaluation of a student inter-professional training ward, Journal of Inter-professional Care, 25, pp. 328-332.

Reeves, S., Zwarenstein, M., Goldman, J., Barr, H., Freeth, D., Hammick M. \& Koppel, I. (2008) Interprofessional education: effects on professional practice and health care outcomes, Cochrane Database Systematic Review, 23, CD002213.

Roberto, M.A. \& Levesque, L.C. (2005) Making change initiatives stick, MIT Sloan Management Review, 46, pp. 53-60.

Schmidt, H.G. (1983) Problem-based learning: rationale and description, Medical Education, 17, pp. 11-16.

UNESCO Asia and Pacific Regional Bureau for Education (2002). Learning to be: A holistic and integrated approach to values education for human development: Core values and the valuing process for developing innovative practices for values education toward international 
understanding and a culture of peace (UNESCOAPNIEVE Sourcebook, No. 2), Bangkok, Thailand.

Vollmar, H.C., Schürer-Maly, C.C., Frahne, J., Lelgemann, M. \& Butzlaff, M (2006) An e-learning platform for guideline implementation-evidenceand case-based knowledge translation via the internet, Methods of Information in Medicine, 45, pp. 389-396.

Wilkerson, L. \& Irby, D. (1998) Strategies for improving teaching practices: a comprehensive approach to faculty development, Academic Medicine, 73, pp. 403-407.
Wilkinson, A., While, A.E. \& Roberts, J. (2009) Measurement of information and communication technology experience and attitudes to e-learning of students in health care professions: integrative review, Journal of Advanced Nursing, 65, pp. 755-772.

Zaini, R.G., Bin Abdulrahman, K., Al-Khotani, A., AlHayani, A., Al-Alwan, I. \& Jastaniah, S. (2011) Saudi Meds: A competence specification for Saudi medical graduates, Medical Teacher, 33, pp. 582-584. 